\title{
Genetic analysis of the larval optic nerve projection in Drosophila
}

\author{
Dietmar Schmucker ${ }^{\mathbf{1}, 2}$, Herbert Jäckle ${ }^{2}$ and Ulrike Gaul ${ }^{1}$ \\ ${ }^{1}$ Rockefeller University, Laboratory of Developmental Neurogenetics, 1230 York Avenue, New York, NY 10021, USA \\ ${ }^{2}$ Max-Planck Institut für biophysikalische Chemie, Abteilung Molekulare Entwicklungsbiologie, Am Fassberg, D-37077 Göttingen, \\ Germany
}

\section{SUMMARY}

The Drosophila larval optic nerve, called Bolwig's nerve (BN), projects into the central brain along a simple invariant path. The growth of the $\mathrm{BN}$ proceeds in three phases, during which the nerve changes direction at two intermediate targets, P1 and P2. Here we show that the projection of the $\mathrm{BN}$ is amenable to genetic dissection. In a mutagenesis screen, we have isolated mutations in 13 genes that disrupt the $\mathrm{BN}$ projection in distinct phases of its development. The mutant phenotypes in combination with the expression patterns of corresponding candidate genes define cellular components necessary for directing the growth of the BN toward P2 and for redirecting its growth at $\mathrm{P} 2$, and reveal developmental strategies employed in the establishment of the $\mathrm{BN}$ projection.

Key words: Drosophila, optic nerve, Bolwig's nerve, genetic analysis

\section{INTRODUCTION}

How neurons establish connections with their often distant targets is one of the fundamental questions of developmental neurobiology (Dodd and Jessell, 1988; Goodman and Shatz, 1993). Most often, it is the axon that navigates this distance through directed growth at its tip. In some cases, however, the cell bodies themselves migrate toward their final location after axonal contacts have first been established (Simon and Lumsden, 1993). Navigation of axons - and possibly the migration of cell bodies - is widely believed to be steered by the spatial distribution of attractive and repulsive cues and by selective adhesion. The nature of these cues is diverse: gradients of diffusible chemicals, local extracellular signals and cell-associated cues (reviewed in Goodman, 1996). Cellassociated cues include guidepost cells, which may represent undifferentiated neurons or glial cells, as well as tracts of other fibers (Bentley and Keshishian, 1982).

In recent years, several families of molecules have been identified that are involved in axonal guidance, including Netrins (Serafini et al., 1994; Kennedy et al., 1994), Semaphorins (Kolodkin et al., 1993; Lou et al., 1993), Eph receptors and their ligands (Cheng et al., 1995; Drescher et al., 1995), and adhesion molecules (CAMs, Cadherins; Grenningloh et al., 1990; Grumet, 1991). While much has been learned about the molecular components involved in the establishment of neuronal connectivity, we are still far from a mechanistic understanding of even simple pathfinding paradigms in vivo. An important prerequisite for testing the central tenets of axon guidance is a simple experimental system, namely an invariant path of axonal growth and easily identifiable intermediate targets at which axons change the direction of their growth. Previously described axon guidance models in the Drosophila embryo include the CNS (Seeger, 1994), the motor neuron projection (VanVactor et al., 1993; Bate and Broadie, 1995) and the PNS (Salzberg et al., 1994; Kolodziej et al., 1995). Here we would like to advocate the larval visual system of Drosophila as a simple model to study the cellular and the molecular mechanisms of axonal growth and pathfinding using a combination of cellular, genetic and molecular approaches. The larval visual system offers the opportunity to study the projection of a small group of photoreceptor neurons both with respect to their pathfinding and their fasciculation into a nerve. The availability of an early and specific marker for the larval visual system furthermore permits study of these processes selectively and at very high resolution.

The main photoreceptive organs of the larval visual system of flies have first been described for Musca domestica by N. Bolwig (Bolwig, 1946) and are therefore referred to as Bolwig's organs (BO) (Steller et al., 1987). The BOs are a pair of photoreceptive organs, which are located bilaterally in a dorsomedial position in the head of the Drosophila larva. Each BO consists of only 12 photoreceptors, unipolar neurons, which project ipsilaterally along an invariant pathway via a single optic nerve, the Bolwig nerve (BN). The BN extends posteriorly from the $\mathrm{BO}$ to the ipsilateral brain hemisphere, enters the brain in the vicinity of the optic lobe anlagen (OLA), the primordia of the adult optic lobes, and grows toward a small target area in the central brain (Fig. 1).

The embryonic development of the BO and the OLA are correlated both spatially and temporally. The two structures arise from the same location in the ectoderm of the embryonic head region (Green et al., 1993) and the projections from the BO contact the OLA early in development, while the two cell groups are in close proximity to one another. These initial axonal projections are thought to be maintained during the morphogenetic separation of BO and OLA due to the incorporation of the OLA into the ventral brain and the complex process of head morphogenesis. The growth of the BN toward its target in the central brain is thought to be guided by the 
Fig. 1. The BO and its projection into the brain. (A) $\alpha-\beta$ galactosidase staining of a stage 16 embryo carrying the BS23 reporter gene. The cluster of $\mathrm{BO}$ photoreceptors (arrow) and the entire projection of the BN (arrowheads) are visible. (B) $\alpha-\mathrm{Kr} / 22 \mathrm{C} 10$ double staining of a wild-type stage 15 embryo. The Kr-expressing BO is part of the 22C10-expressing PNS and is located dorsally and posteriorly (arrow) of the antennomaxillary complex (arrowhead). Scale bar, $30 \mu \mathrm{m}$ (A); $10 \mu \mathrm{m}$ (B).
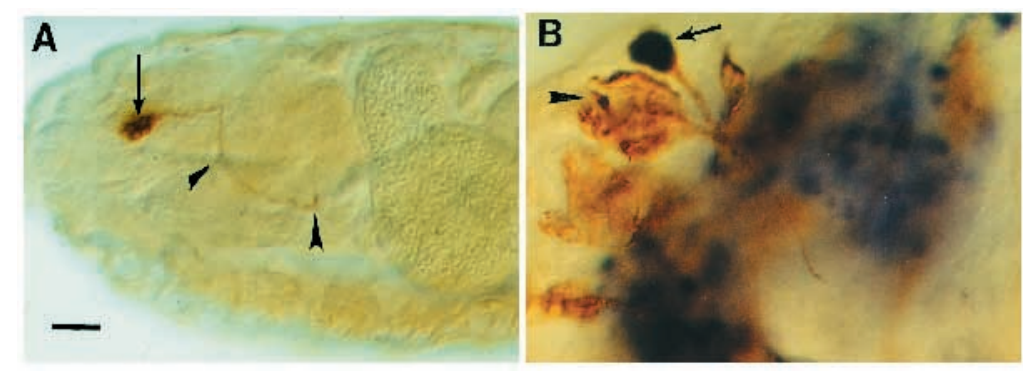

axons of the so-called optic lobe pioneer (OLP) cells (Campos et al., 1995).

Thus far, three genes have been implicated in the development of the BO/BN projection, Krüppel ( $K r$, Schmucker et al., 1992), glass (gl, Moses et al., 1989) and disconnected (disco, Steller et al., 1987; Heilig et al., 1991; Lee et al., 1991). All three genes encode transcription factors with $\mathrm{Zn}$-finger motifs. $g l$ and $K r$ are expressed in the BO precursor cells. While $g l$ seems to be required for proper differentiation of $\mathrm{BO}$ cells into photoreceptors, $K r$ is likely to be involved in several different aspects of $\mathrm{BO} / \mathrm{BN}$ development. In contrast, disco is not expressed in the cells of the $\mathrm{BO}$, but rather in a large portion of the OLA, which represents the cellular substratum for most of the growth of the BN (Lee et al., 1991). In disco mutant embryos, a variety of $\mathrm{BN}$ projection defects are observed. The $\mathrm{BN}$ defasciculates and either projects to the OLA but fails to recognize and connect with its appropriate synaptic target cells, or projects to ectopic locations far from the OLA . In addition, the cohesion of the BO is impaired (Steller et al., 1987). However, because of the wide expression of disco, its precise

Fig. 2. Early development of BO/BN, eOS and OLA. (A-D) BO and OLA derive from a common region in the posterior head. (A) $\alpha$ FasII (green) and $\alpha-\mathrm{Kr}$ (red) double staining of a stage 12 wild-type embryo. A cluster of 5-6 Kr-expressing BO precursor cells (nuclear staining in red, arrow) is found in the posterior head region; these cells also express FasII (membrane staining in green, arrowhead). Strong $\mathrm{Kr}$ expression is also visible in few muscle precursor cells of the neighboring thoracic segments. (B-D) $\alpha$ - $\beta$-galactosidase (red) and $\alpha-\mathrm{Kr}$ (green) double staining of an early stage 13 embryo carrying the $\mathrm{C} 50.1 \mathrm{~S} 1$ disco enhancertrap insertion. BO (green, arrow) and OLA precursors (red, cells anterior of BO) can be discriminated by their differential expression of $\mathrm{Kr}$ and disco. (B,C) Lateral and dorsal views of the head region of a stage 13 embryo, respectively. (D) High magnification of the BO precursor cells from embryo in (B). Kr-expressing cells (green) are immediately adjacent but not overlapping with disco-expressing cells (red). (E) A stage 13 embryo carrying the BS23 reporter gene stained with $\alpha$ - $\beta$-galactosidase (green) and $\alpha$-FasII (red) antibodies. Due to co-expression of the $\beta$-galactosidase and FasII, the BO and its nascent axons appear in yellow. The eOS only expresses FasII and therefore appears in red. Young BN axons are visible growing along the eOS toward the OLA. A single axon has reached the position P1 at the margin of the OLA (arrow); a second axon has just begun to grow in the same direction (arrowhead). (F-G) Stage 13 embryos carrying the BS23 reporter stained with $\alpha-\beta$ galactosidase antibodies viewed by Nomarski optics.

(F) Dorsolateral view. BN axons fasciculate early on and project in a posterior and medial direction. (G) Ventral view. BN axons (arrow indicates distal tip of axons) grow along the eOS (arrowheads) toward the invaginated OLA (ola). Scale bar in A: $5 \mu \mathrm{m}$ (A); $10 \mu \mathrm{m}$ (B,C,E); $3 \mu \mathrm{m}(\mathrm{D})$; scale bar in F: $16 \mu \mathrm{m} ; 10 \mu \mathrm{m}(\mathrm{G})$. role in the establishment of the $\mathrm{BN}$ projection is not well understood (Campos et al., 1995).

Here we present a developmental and genetic analysis of the $\mathrm{BN}$ projection. We show that the establishment of the projection occurs in three distinct phases during which the nerve contacts two intermediate targets at which it redirects its growth. We then present the results from a mutagenesis screen designed to identify genes involved in axonal growth and pathfinding of the BN. We have identified 13 genes, which disrupt the $\mathrm{BN}$ projection in different phases of its development. We focus our description on the projection defects of representative mutants and the expression patterns of the genes that they likely disrupt. By comparing the mutant phenotypes with the expression patterns, we are able to identify candidates for essential cellular components and assess their role in the normal projection of the nerve.

\section{MATERIALS AND METHODS}

\section{Drosophila strains}

Genetic markers and chromosomes are described in Lindsley and Zimm (1992). Lethal P enhancer trap mutations on the third chromo-
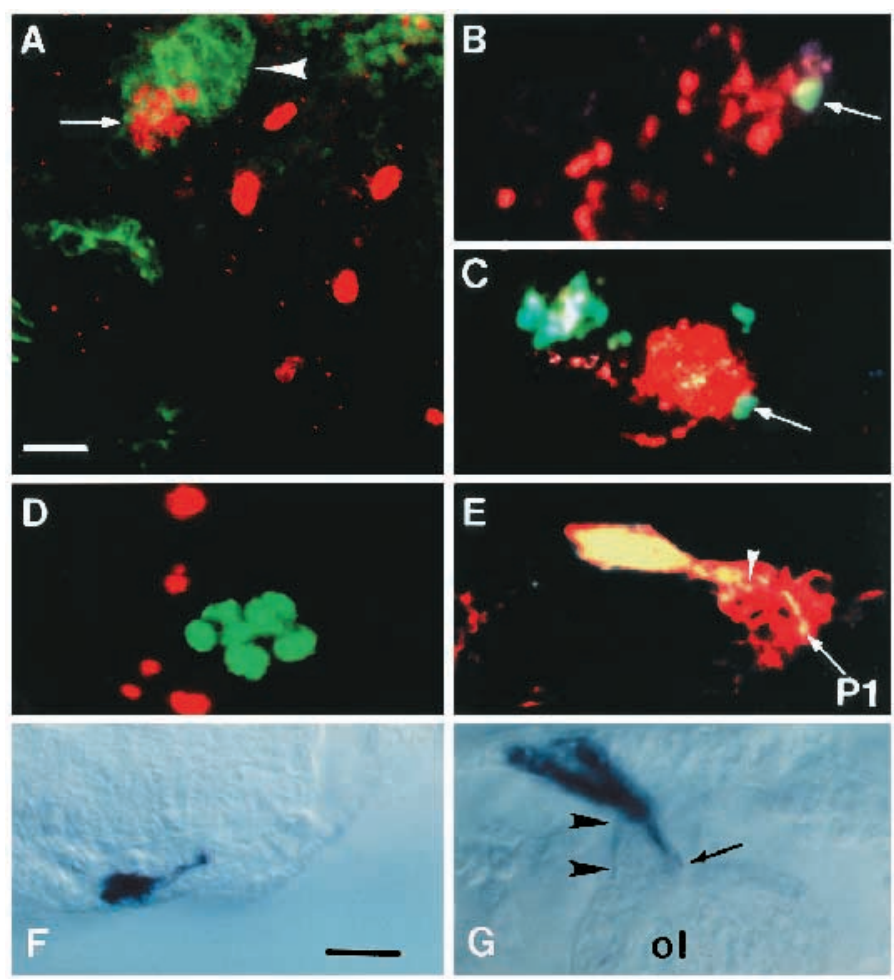
some were provided by A. Spradling and are included in the Berkeley Drosophila Genome Project (BDGP).

\section{EMS mutagenesis and screening procedure}

Males of the transgenic marker line BS23 (Schmucker et al., 1992) were treated with $25 \mathrm{mM}$ EMS using a standard protocol (Roberts, 1986). Mutagenized males were crossed en masse to $e, D T S 4 / T M 3$, $S b, h b B$ females. Single $\mathrm{F}_{1}$ males $B S 23 / T M 3, S b, h b B$ were then crossed to $e, D T S 4 / T M 3, S b, h b B$ females. To facilitate the subsequent establishment of stocks, the crosses were subjected to a 2 day temperature shift to $29^{\circ} \mathrm{C}$ to kill the progeny bearing a DTS4 chromosome. $\mathrm{F}_{2}$ siblings of the genotype $B S 23 / T M 3, S b, h b B$ were crossed to each other, to establish a balanced stock. 0-17 hour embryo collections of the balanced stocks were screened for defects in $\mathrm{BO} / \mathrm{BN}$ development by histochemical staining for $\beta$-galactosidase activity (Klämbt et al., 1991). Embryos from each line were analysed under the dissecting microscope, and those showing any abnormalities in their $\mathrm{BN}$ projection were examined more carefully at higher magnification under a compound microscope (Zeiss Axiophot). Homozygous mutant embryos were easily recognizable by the absence of the TM3 $h b B$ balancer, which harbors a $h b-l a c Z$ reporter gene.

Since the establishment of the BN projection is tightly linked to morphogenetic movements in the head, we carefully examined the mutations isolated in the primary screen for any defects in head segmentation and/or head involution as well as for general body pattern defects. As judged by morphological examination under Nomarski optics and 22C10 immunostainings, 27 mutations showed gross body pattern or nervous system defects. The remaining 45 mutations were tested for embryonic head defects by examining $\alpha$-Engrailed stainings (Schmidt-Ott and Technau, 1992), and for defects in optic lobe formation by examining the expression of the markers Crumbs (Yanoussi-Hartenstein et al., 1993), FasII (VanVactor et al., 1993) and the disco enhancer trap line C50.1S1 (Heilig et al., 1991). Thus additional 27 mutations were eliminated because they showed either head involution defects that interfered with BO development or abnormally small OLAs or OLAs that failed to invaginate. Such mutations are likely to affect BN development only indirectly.

Mutations with similar phenotypes were tested for complementation of lethality. Members of three different complementation groups (II-F1,XI-E2 and $V-D 1)$ were mapped by meiotic recombination using the $r u, t h, s t, c u, s r, e, c a$ marker chromosomes. II-Fl was found to be uncovered by the deficiency $\operatorname{Df}(3) \mathrm{XM} 3$ and fails to complement the $\mathrm{P}$ enhancertrap insertion l(3)04505 (BDGP). The mutations XI-E2 and $V$-D 1 failed to complement mutations in pointed and prospero, respectively. The chromosomal map positions of the other EMS mutations isolated in the screen have not yet been determined.
Fig. 3. The projection of the $\mathrm{BN}$ from $\mathrm{P} 1$ to $\mathrm{P} 2$ and into the central brain. (A,C,E) $\alpha$-Kr (dark blue) and $\alpha$-FasII (brown) double stainings of stage 14, 15 and 16 wild-type embryos, respectively. Apart from the $\mathrm{BO}, \mathrm{Kr}$ expression is found in many cells of the CNS. (B,D,G,H) $\alpha-22 \mathrm{C} 10$ stainings of stages $14,15,16$ and early first instar, respectively. (B,D) Whole-mount embryos; $(\mathrm{G}, \mathrm{H})$ paraffin sections. (F) $\alpha$-Bsh/22C10 double staining of stage 16 wild-type embryo. (A,B) While the morphogenetic separation of BO (bold arrow) and OLA (arrowhead) proceeds, the projection of the BN to $\mathrm{P} 1$ (arrow) is maintained. (C,D) While the distance between $\mathrm{BO}$ and OLA continuously increases due to intercalary growth of the $\mathrm{BN}$, a second phase of directed $\mathrm{BN}$ growth begins. (D) A few BN axons (arrows) emanating from a a thicker shaft (arrowhead) are visibly growing beyond P1 (arrowhead) and taking a sharp turn towards posterior (compare BN tip in B and D). (E) Concomitant with head involution, the $\mathrm{BO}$ (bold arrow) is displaced further anteriorly relative to the OLA (arrowhead; compare A, C and E). During this process, the $\mathrm{BN}$ elongates substantially, as does the FasIIexpressing eOS. Note that FasII expression is lost from the eOS during stages 15/16 (compare A, C and E). (F) A single Bsh-expressing cell in the OLA (arrow) marks the intermediate target $\mathrm{P} 2$, which is contacted by the $\mathrm{BN}$ during stage 16. (G) The BN leaves the brain surface at P2 (arrowhead) and grows into the central brain (arrow indicates nerve tip). (H) In early first instar larvae, the BN has reached target cells in the central brain (arrow). The OLPs (arrowhead) are contacted by the $\mathrm{BN}$, and their axons fasciculate. Scale bar, $16 \mu \mathrm{m}$ (A-E); $10 \mu \mathrm{m}$ (F-H).
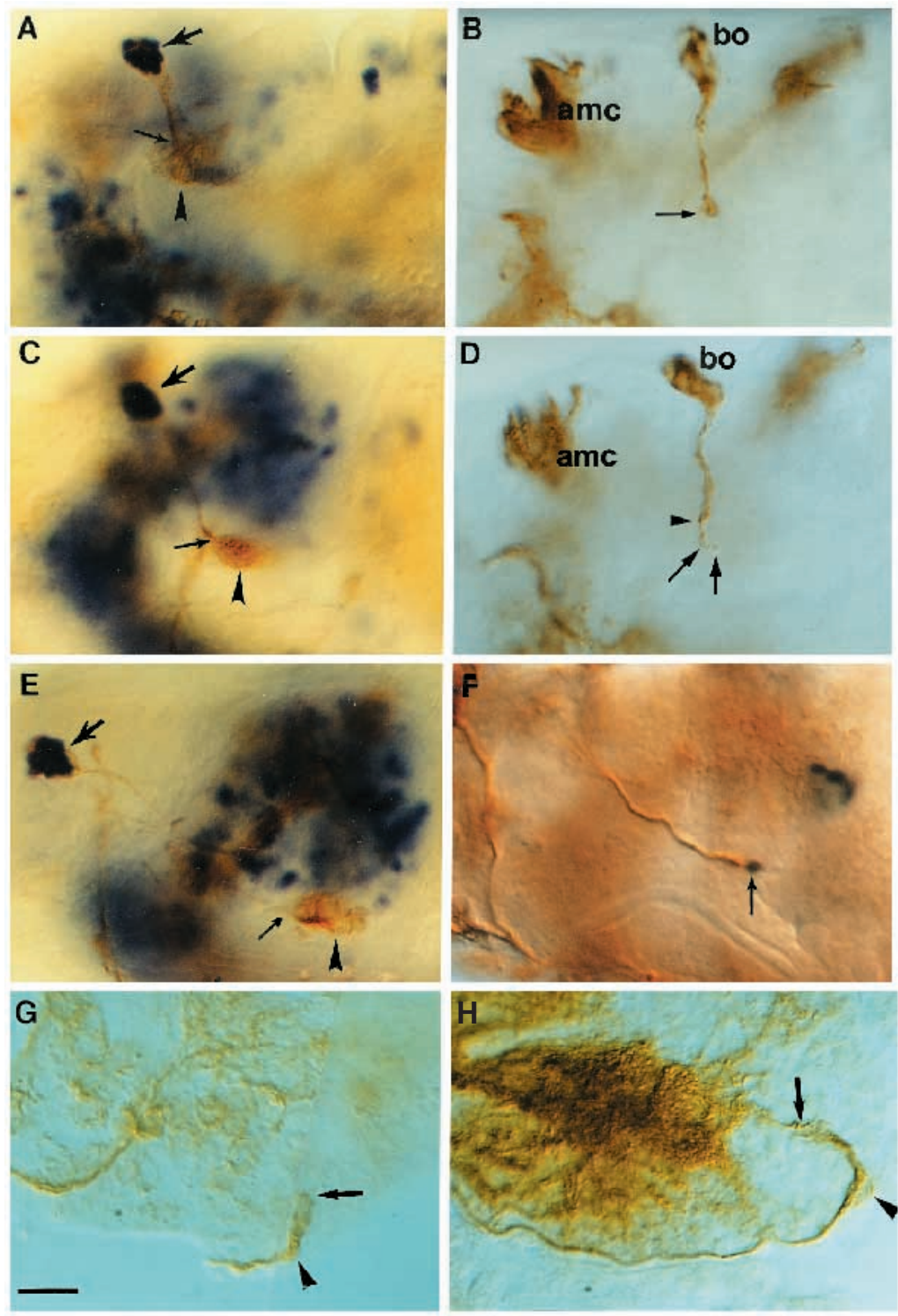


\section{Screening of $\mathbf{P}$ enhancer trap lines}

Approximately 300 lethal $P$ enhancer trap insertions on the third chromosome (A. Spradling) were examined for embryonic expression using $\alpha$ - $\beta$-galactosidase antibodies (S. Elend and H. Jäckle, unpublished data). Enhancer trap lines with expression near or in the BO and OLA were tested for phenotypic defects of the $\mathrm{BN}$ projection by $22 \mathrm{C} 10$ immunostainings. In this screen, we identified the P enhancer trap lines $l(3) 03550(s c d), l(3) 03203(\mathrm{pkl})$ and $l(3) 05845$ (argos) (see Table 1).

\section{P element reversions}

P elements were mobilized in matings with a stable transposase source (Robertson et al., 1988). In each reversion experiment, 100 independent $r y$ lines were established and tested for reversion of lethality and $\mathrm{BN}$ projection defects. The $\mathrm{P}$ enhancer trap line $l(3) 3203$ is in fact semi-lethal; the semi-lethality is uncovered by the deficiency $\operatorname{Df}(3)$ pXT9. In the reversion experiment for $l(3) 3203$, we also recovered lethal excision alleles. The mutant phenotype of several tested lethal excision alleles is similar to that of the original $\mathrm{P}$ insertion and is not enhanced in trans to the deficiency, suggesting that the original $\mathrm{P}$ insertion as well as the newly recovered excision alleles represent strong hypomorphic, if not amorphic, alleles of the $p k l$ locus. In the case of $l(3) 03550$, reversion of the $P\left(r y^{+}\right)$element was also carried out by X-ray mutagenesis in order to recover deletions of the $s c d$ locus (Roberts, 1986). We screened 30,000 mutagenized chromosomes and found 7 chromosomes that had lost the $r y^{+}$marker and failed to complement the lethality of $l(3) 03550.4$ of these lethal revertants also fail to complement the lethality of neighboring lethal $\mathrm{P}$ insertions $(l(3) 03929 ; l(3) 04083)$, and are therefore likely to represent deficiencies in the $88 \mathrm{E}-\mathrm{F}$ region.

\section{Immunostainings}

Immunohistochemistry of embryos was carried out using standard procedures (Schmucker et al., 1992). The following primary antibodies were used: rabbit $\alpha$ - $\beta$-galactosidase (1:1000; Cappel); rabbit $\alpha-\operatorname{Kr}$ (1:500; (Hoch et al., 1994); mouse mAb $\alpha$-Fasciclin II (1:20; (VanVactor et al., 1993); mouse mAb 22C10 (1:50; (Fujita et al., 1982); mouse mAb 24B10 (1:10; VanVactor et al., 1988; rabbit $\alpha$ Repo (1:500; Campbell et al., 1994). Detection of primary antibodies was carried out using the ABC-Elite kit (secondary antibodies 1:1000; Vectastain). In double label experiments, we used alkaline phosphatase- and peroxidase-conjugated secondary antibodies (1:2000; Jackson Immunoresearch), or, two peroxidase-conjugated secondary antibodies consecutively. In the latter case, first staining reaction was carried out in the presence of $0.1 \% \mathrm{NiCl}$, which yields a black reaction product. Embryos were mounted in Araldite (Serva) and embedded in glass capillaries as described previously (Schmidt-Ott and Technau, 1992). For confocal microscopy, primary antibodies were detected by FITC- or CY3-conjugated secondary antibodies (1:100; Jackson Immunoresearch). Embryos were mounted in Vectashield (Vector) and immunofluorescent images were collected on a Bio-Rad MRC 600 .

\section{RESULTS}

In the first part of this section, we describe the development of the $\mathrm{BO}$ and the establishment of the $\mathrm{BN}$. We begin with a description of the events that lead to cell fate determination and organogenesis of the $\mathrm{BO}$, and continue with a detailed account of the development of the $\mathrm{BN}$ projection, including the initial outgrowth of axons and their fasciculation, the elongation of the $\mathrm{BN}$, and its navigation and ingrowth into the central brain. In the second part, we present the results from our mutagenesis screen, which reveal a number of genetic components required for different aspects of the establishment of the BN projection.

\section{Development of BO and BN projection}

Cell fate determination and organogenesis

The BO neurons derive from a coherent group of approximately 30 cells in the posterior head region of a stage 12 embryo (all staging according to Campos-Ortega and Hartenstein (1985), and can be visualized by the expression of the cell membrane antigen Fasciclin II (FasII; Grenningloh et al., 1991) (Fig. 2A). Four to six cells located at the ventral lateral margin of this cluster of FasII-positive cells represent BO precursors, while the remainder represent precursors of the optic lobe anlagen (OLA) (Fig. 2A), which will become part of the adult optic lobes. At late stage 12, BO and neighboring OLA precursor cells are morphologically indistinguishable, but can be differentiated by their expression of specific molecular markers. The BO precursors are marked by expression of the $K r$ gene (Schmucker et al., 1992), while the neighboring OLA cells (Fig. 2B-D) are marked by expression of the disco gene (Lee et al., 1991). From this stage onwards, BO development can also be followed by the expression of a lac Z reporter gene driven by a $\mathrm{BO}$-specific enhancer element of the $K r$ gene (BS23 reporter gene; Hoch et al., 1990), which exclusively labels the cell bodies and axons of the BO (Fig. 2E-G; see below).

During stage 13 the $\mathrm{BO}$ precursors elongate, become polarized and form a distinct cell cluster (Fig. 2E). At the same time the BO cells separate from the OLA precursors. The OLA cells detach from the superficial ectoderm and invaginate in a process called optic lobe invagination (Campos-Ortega and Hartenstein, 1985). The BO precursor cells, as well as a few of the adjacent FasII-positive cells, remain at the surface ectoderm and form a cellular bridge between $\mathrm{BO}$ neurons and the invaginating OLA cells (Fig. 2E,G). We refer to this cellular bridge as the 'embryonic optic stalk' (eOS). During the morphogenetic separation of BO and OLA, the relative position between the two structures changes such that the $\mathrm{BO}$ comes to lie anterior to the OLA (Fig. 3A-E compare with Fig. 2B-D). Whether this rearrangement is a secondary consequence of optic lobe invagination or due to an active migration of the $\mathrm{BO}$ is unclear.

During stages 12 to 14 , the number of $\mathrm{Kr}$-expressing cells in the BO increases from 4-6 in the anlage to the final complement of 12 cells in the differentiated organ (compare Figs $2 \mathrm{D}, \mathrm{G}$ and $3 \mathrm{~B}$ ). Whether this increase is due to cell division or involves recruitment of additional cells is not clear. During stage $13 / 14$, the cell bodies of the BO form the tightly packed rosette characteristic of the mature organ (Fig. 3A,B). This morphogenetic event is preceded by the neuronal differentiation of BO cells during stage 13 as shown by expression of the 22C10 antigen (Fig. 3B). The final differentiation of BO cells into photoreceptors becomes apparent at stage 15 by their expression of Chaoptin, a membrane protein exclusively expressed in photoreceptor cells (VanVactor et al., 1988) and detected by the monoclonal antibody 24B10.

\section{Axonal outgrowth and nerve fasciculation}

A single posteriorly projecting axon can be visualized in the BS23 line during early stage 13 (Schmucker et al., 1992). As additional BO cells undergo axonogenesis, their axons join a leading axon and fasciculate to form the BN (Fig. 2E). The sequential outgrowth of $\mathrm{BN}$ axons is paralleled by a sequential 
expression of the $22 \mathrm{C} 10$ antigen in the corresponding $\mathrm{BO}$ cells (Schmucker et al., 1992).

The nascent BN initially extends posteriorly (Fig. 2E) and then ventrally as the separation between $\mathrm{BO}$ and OLA proceeds (Fig. 3A-D). During stage 13, the BN grows along the FasIIexpressing cells of the eOS (Figs 2E, 3A), suggesting that the eOS represents a cellular substratum for the posteriorly directed growth of BN axons. By the end of stage 13, the distal tip of the fasciculated $\mathrm{BN}$ has reached the base of the eOS at the margin of the invaginated OLA. The position at which the distal tip of the BN contacts the OLA margin will be referred to as P1 (Fig. 2E).

\section{Nerve elongation and directional growth}

With the onset of stage 14 , the process of head involution begins (Campos-Ortega and Hartenstein, 1985), which leads to an extensive movement of cells in the embryonic head. This complex process continues until the end of embryogenesis and is poorly understood. Concomitant with the morphogenetic movements of head involution, the BO is first displaced to a more dorsal and then to a more anteromedial location (Fig. 3A-F).

Between early stage 14 and midstage 16 , the length of the $\mathrm{BN}$ between the somata of the $\mathrm{BO}$ and $\mathrm{P} 1$ (Fig. 3A,B) increases from $10 \mu \mathrm{m}$ to over $70 \mu \mathrm{m}$ (Fig. 3E). Considering that this elongation occurs after the distal end of the BN has already established its contact with OLA cells, this severalfold increase in the length of the BN is most likely due to intercalary growth rather than axonal growth at the tip of the BN. Based on their electron microscopic studies, Green et al. (1993) have suggested that this substantial elongation of the $\mathrm{BN}$ is driven by the displacement of the $\mathrm{BO}$ during head involution. However, whether the displacement of the BO is entirely a consequence of head involution or at least partially due to an active migration of the $\mathrm{BO}$ cell bodies is presently unknown.

During stage 14 , the $\mathrm{BN}$ begins with a directed growth beyond P1, while the intercalary growth between $\mathrm{BO}$ cell bodies and $\mathrm{P} 1$ is still continuing (Fig. 3C,E). This process is distinct from the nerve elongation described above, since now the distal tip of the $\mathrm{BN}$ is growing by extending axonal processes beyond P1. As shown in Fig. 3D, axonal extensions emanate as relatively thin processes from a comparatively thick shaft which remains attached to $\mathrm{P} 1$. These axonal extensions grow in a sharp turn $\left(60^{\circ}-90^{\circ}\right)$ towards posterior. The axons grow on the OLA surface in posterior/medial direction for about $35-40 \mu \mathrm{m}$. At stage 16 , they reach a position marked by a single cell, which expresses the brain-specific homeobox (bsh) gene (Fig. 3F) during stages 15 and 16 (Jones and McGinnis, 1993). We refer to the position marked by the Bshexpressing cell as $\mathrm{P} 2$.

\section{Ingrowth into the central brain}

Upon reaching position $\mathrm{P} 2$, growth of the $\mathrm{BN}$ stalls for some time and the distal tip of the nerve changes its morphology; while the tip of the nerve is rather blunt during its growth on the OLA surface, it now shows a more elaborate growth cone with extended filopodia-like processes at P2. These processes are very thin and cover an area of no more than two cell diameters (not shown). When nerve growth later resumes during stage 16, the distal end of the BN leaves the brain surface in a sharp turn $\left(>90^{\circ}\right)$ and grows into the central brain (Fig. 3G) to reach a small group of synaptic target cells (Fig. $3 \mathrm{H}$ ).

At late stage 16, three 22C10-expressing cells are seen at the periphery of the OLA, which are termed optic lobe pioneer (OLP) cells (Fig. 3H; Tix et al., 1989). One of the OLPs is identical with the Bsh-expressing cell at position P2 (Campos et al., 1995). During its growth into the central brain, the BN remains in close contact with the OLP axons. We do not know, however, whether the OLP axons become part of the BN from $\mathrm{P} 2$ onwards or whether they in fact pioneer the projection of the $\mathrm{BN}$ into the central brain. A careful comparison of the time course of the OLP projection into the brain with that of the central projection of the $\mathrm{BN}$ will be necessary to distinguish between these two alternatives.

\section{Isolation of mutations affecting BO and BN development}

The identification of characteristic cellular landmarks along the $\mathrm{BN}$ pathway and the availability of the BS23 marker line, which permits the visualization of the entire projection in a simple histochemical procedure, encouraged us to use the $\mathrm{BO} / \mathrm{BN}$ system to identify genes specifically required for axonal growth and pathfinding with a mutagenic approach.

In order to facilitate the visualization of the $\mathrm{BN}$, flies

Table 1. Mutations affecting the $\mathrm{BN}$ projection

\begin{tabular}{|c|c|c|c|}
\hline & Alleles & Locus & Mutation \\
\hline $\begin{array}{l}\text { Group 1. Mutations that affect both } \mathrm{BO} \text { cell clustering and } \mathrm{BN} \text { projection } \\
\rightarrow \text { orientation of the } \mathrm{BO} \text { cells abnormal, random projection of } \mathrm{BN} \text { axons }\end{array}$ & $V I-G 6$ & aloof (alf) & EMS \\
\hline$\rightarrow$ cohesion of the BO disrupted, misprojection and defasciculation of the BN & $\begin{array}{l}l(3) 03550 \\
V I I-I 8, I I I-A 2 \\
V I-C 4 \\
I I I-A 4, I I I-C 3, V-D 1 \\
l(3) 05845\end{array}$ & $\begin{array}{l}\text { scattered }(\text { scd }) \\
\quad- \\
\quad- \\
\text { prospero (pros) } \\
\text { argos }\end{array}$ & $\begin{array}{l}\mathrm{P} \\
\text { EMS } \\
\text { EMS } \\
\text { EMS } \\
\mathrm{P}\end{array}$ \\
\hline $\begin{array}{l}\text { Group 2. Mutations that affect the BN projection only } \\
\rightarrow \text { defects visible with onset of axonogenesis }\end{array}$ & $I I-F 1, l(3) 04505$ & abstrakt (abs) & EMS, P \\
\hline$\rightarrow$ defects visible from $\mathrm{P} 1$ onwards & $\begin{array}{l}X I-E 2 \\
X I I-F 3, I-D 8\end{array}$ & $\begin{array}{l}\text { pointed (pnt) } \\
\quad-\end{array}$ & $\begin{array}{l}\text { EMS } \\
\text { EMS }\end{array}$ \\
\hline$\rightarrow$ defects visible at $\mathrm{P} 2$ & $\begin{array}{l}l(3) 03203 \\
\text { VIII-E7 } \\
I I-E 9 \\
\text { VII-C7 }\end{array}$ & $\begin{array}{l}\text { pumuckel (pkl) } \\
\quad- \\
- \\
-\end{array}$ & $\begin{array}{l}\text { P } \\
\text { EMS } \\
\text { EMS } \\
\text { EMS }\end{array}$ \\
\hline
\end{tabular}



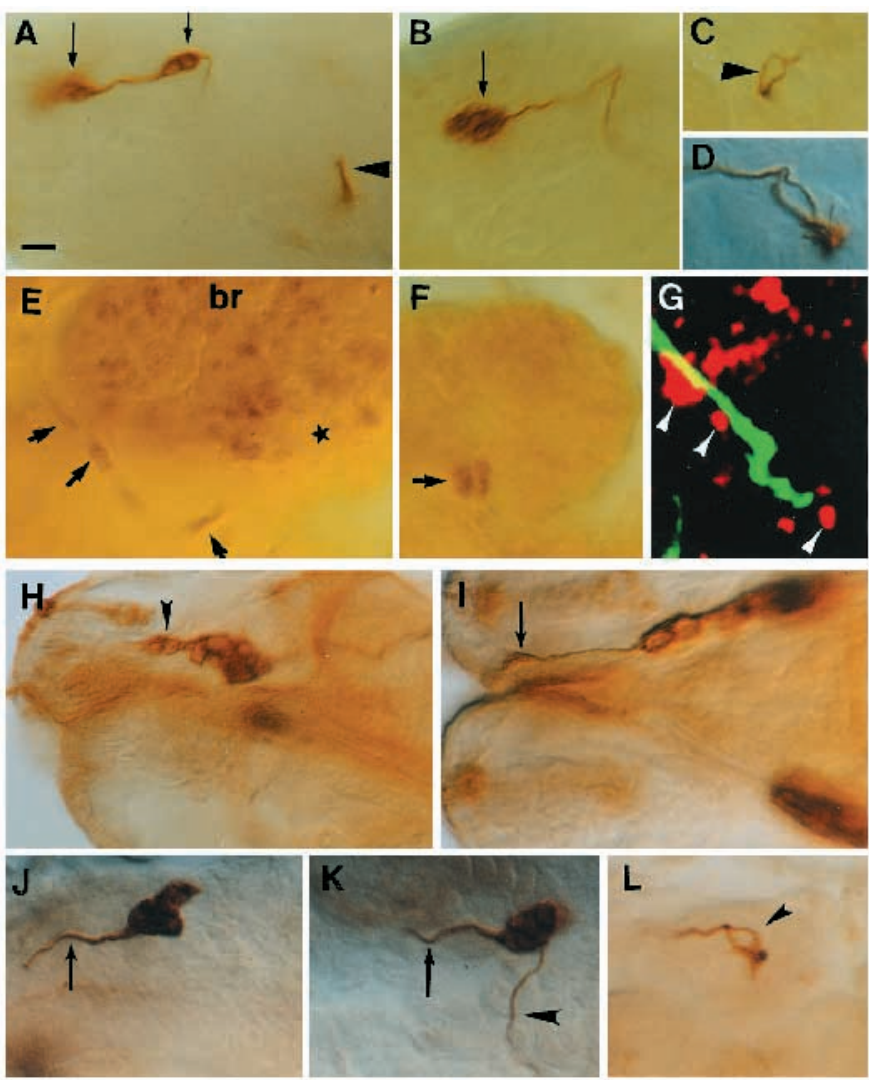

Fig. 4. $s c d$ and alf affect both the formation of the BO and the projection of the BN. (A-D) BO/BN defects in $s c d$ mutant embryos. (E-G) $\beta$-galactosidase reporter gene expression of embryos heterozygous for the $s c d \mathrm{P}$ enhancertrap insertion l(3)3550. (H-L) BO/BN aberrations in alf mutant embryos. (A-D) 24B10 stainings of $s c d$ mutant embryos at stage 16. (A,B) The BOs in $s c d$ mutant embryos show a variable disruption of the $\mathrm{BO}$ cell clustering. In some embryos, the $\mathrm{BO}$ is disrupted and photoreceptors are displaced along the BN path (arrows, A), while in others the $\mathrm{BO}$ appears intact and indistinguishable from wild type (arrow, B); compare also to Fig. 1 (A). The arrowhead in A indicates an ectopically projecting $\mathrm{BN}$ branch. (C,D) In most $s c d$ mutant embryos, the BN defasciculates on the OLA surface. Typically, the defasciculated BN projects aberrantly and forms loop-like structures. (E,F) In the $s c d$ enhancer trap line P3550, $\beta$ galactosidase-expressing cells are found along the path of the $\mathrm{BN}$ (E, arrows), and at the base of the OLA (E, star; F, arrow), as well as in the embryonic brain (br). Shown are two different focal planes of the same embryo. (G) $\alpha$ - $\beta$-galactosidase (red) and $22 \mathrm{C} 10$ (green) double staining of a stage 15 embryo heterozygous for $l(3) 03550$. Several $\beta$-galactosidase-expressing cells are in contact with the BN (arrowheads). (H-L) The alf mutation disrupts photoreceptor cell clustering and results in random projection of photoreceptor axons. 24B10 stainings of stage 16 alf mutant embryos. (H) In alf mutants, the BO cell cluster appears disorganized and several cells are often displaced anteriorly from the main BO cell cluster (arrowhead).

(I-K) Extreme misprojections of the BN can be found.

(I) Anteriorly projecting $\mathrm{BN}$ axons with enlarged growth cones at their tip (arrow). (J) Dorsal and (K) lateral view of the same embryo. The BO is split into two subgroups of photoreceptors, with one anteriorly projecting BN branch (arrow) and the other BN branch (arrowhead) projecting in normal posterior direction along the brain. (L) Even axons that project normally to P1 show defasciculation defects as well as misprojections on the OLA surface. Scale bar, $16 \mu \mathrm{m}$ (A-C,H,J-L); $10 \mu \mathrm{m}$ (D-G, I).

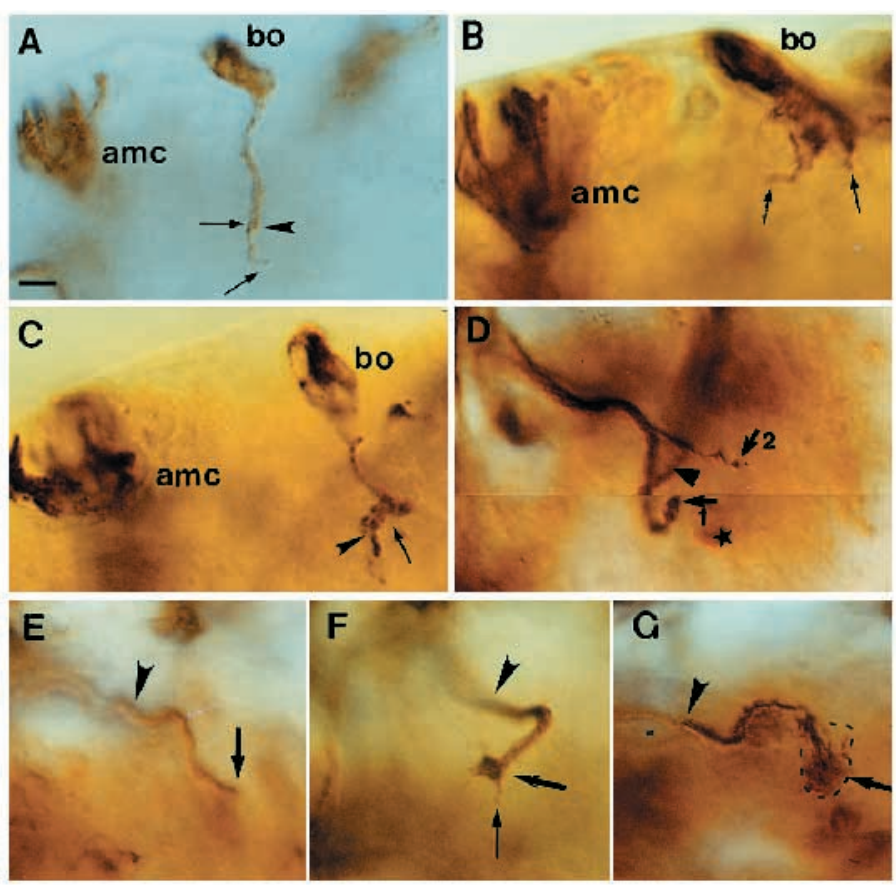

Fig. 5. The $a b s$ mutation disrupts axonal growth of the BN. (A-G) 22C10 stainings of wild-type (A,E) and abs mutant embryos (B-D,F,G). (A-C) The projection of the BN to P1 (arrowhead) is severely abnormal in abs mutant embryos $(\mathrm{B}, \mathrm{C})$ as compared to wild type (A). Shown are two examples of an aberrant BN in a stage 13 (B) and stage 14 (C) abs mutant embryo. The BN often fails to properly fasciculate early on, and thus independent branches are found exploring the entire width of the eOS (B). (C) The mutant BN displays aberrant turns (arrow) along the path to P1 (arrowhead). In addition, the distal part of the BN appears abnormally thick compared to wild type (arrow). (D) Stage 16 abs mutant embryo. Despite these severe early defects, the BN usually establishes the projection to $\mathrm{P} 1$. However, on its way to $\mathrm{P} 2$ (star), the $\mathrm{BN}$ again shows massive defasciculation defects and aberrant projections of the resulting branches (arrows 1 and 2; arrowhead). (E-G) As compared to wild type (E), the morphology of the tip of the $\mathrm{BN}$ is highly abnormal in abs mutant embryos (F,G). In the mutant, the nerve tip is often enlarged (bold arrow, F,G) and forms thin filopodia-like extensions (arrow, F) which may cover a large area of the OLA (dotted line, G). Scale bar, $16 \mu \mathrm{m}$ (A,D-G); $10 \mu \mathrm{m}$ (B,C).

harboring the BS23 transgene were mutagenized using ethylmethanesulfonate (EMS). We generated 2800 lines bearing mutations on the third chromosome and examined these lines for $\mathrm{BN}$ projection defects. In addition, we examined 300 lethal $\mathrm{P}$ element insertions on the third chromosome (obtained from A. Spradling; Drosophila genome project) for BN defects. Among these lines, we identified 76 mutations (72 EMS alleles and 4 P-element insertions) that affect $\mathrm{BO}$ and $\mathrm{BN}$ development (see Materials and Methods). We then used a set of morphological criteria (see Materials and Methods) to assess the specificity of these mutations. Of the 76 mutations, 54 were excluded from further consideration, because they showed either a disruption of the segmented body pattern, abnormalities in head or brain morphology, or defects in optic lobe formation (not shown). The remaining 22 mutations fell into 16 different complementation groups (see Table 1). Four of the mutations could be mapped to the known genes $g l$, pointed (pnt), prospero (pros) and argos (Moses et al., 1989; Klämbt, 1993; Doe et al., 1991; 
Fig. 6. pnt causes misprojections and defasciculation of the BN. (A-C) $\alpha$-Bsh $/ 22 \mathrm{C} 10$ double stainings. (D,E) $\alpha-\beta$ galactosidase stainings of pnt $\mathrm{P}$ enhancertrap lines. (A) In stage 16 wild-type embryos, the $\mathrm{BN}$ projection has reached $\mathrm{P} 2$, which is marked by a single Bsh-expressing cell (arrow). Additional Bsh-expressing cells are found outside the OLA in the embryonic brain (arrowhead). (B) pnt $t^{488}$ mutant embryo at stage 16 . No Bsh-positive cell is found in the OLA and the projection of the BN ends without ever reaching a Bsh-expressing cell. The aberrant $\mathrm{BN}$ does not project to its normal ventromedial position (cross). Note that the other Bsh-expressing cells outside the OLA are present (arrowhead). (C) pnt ${ }^{\Delta 88}$ mutant embryo at stage 15 . At the OLA, the BN has split into two branches (arrow). (D,E) $\alpha$ - $\beta$-galactosidase $/ 22 \mathrm{C} 10$ double stainings of the $p n t$

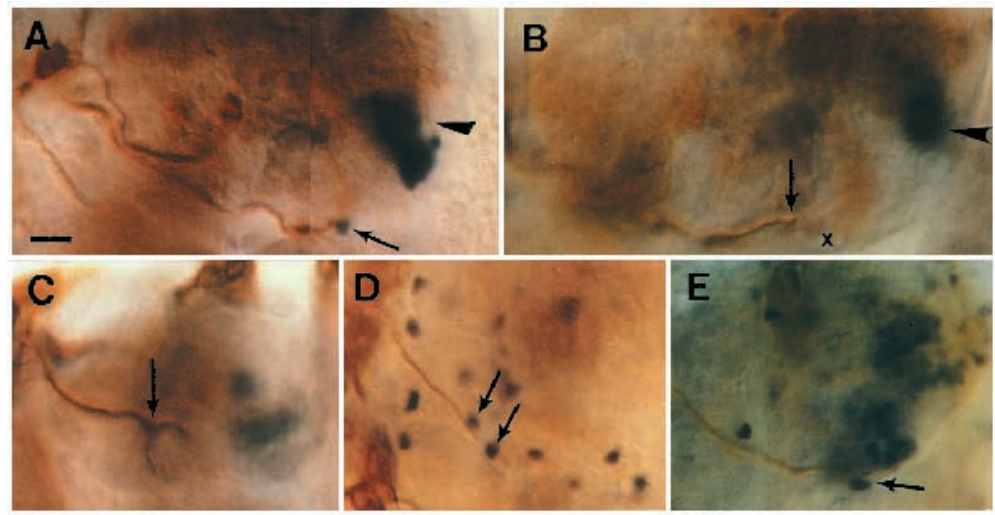
P enhancertrap lines rM254 (D) and $l(3) 7825(\mathrm{E})$ at stage 16. rM254 is an insertion in the P1-promoter and $l(3) 7825$ is an insertion in the P2-promoter of pnt. In the rM254 line, several $\beta$ galactosidase-expressing cells are found along the $\mathrm{BN}$ (arrows, D). In the $l(3) 7825$ line, a few $\beta$-galactosidase-expressing cells are found close to P2 in the posterior portion of the OLA (E). At least one of these cells is in direct contact with the BN (arrow in E). Scale bar, $16 \mu \mathrm{m}$ $(\mathrm{A}, \mathrm{C}, \mathrm{E}) ; 10 \mu \mathrm{m}(\mathrm{B}, \mathrm{D})$

Vaessin et al., 1991; Freeman et al., 1992; Kretzschmar et al., 1992). Mutations in three genes (including $g l$ ) lead to a strongly reduced cell number of the mutant $\mathrm{BO}$. These mutations most likely affect early cell fate determination or cell proliferation processes (D. S., unpublished data).

In the present study, we analyse the remaining 18 mutations (corresponding to 13 genes, see Table 1) that do not alter the size of the $\mathrm{BO}$ or their photoreceptor identity. These mutations, which affect $\mathrm{BO}$ and $\mathrm{BN}$ development, fall into two major phenotypic groups. The first group of mutants show defects in both the formation of the $\mathrm{BO}$ and the projection of the $\mathrm{BN}$, while the second only show defects in the projection of the BN. In the following description, we focus on representative examples from both groups.

\section{Mutations that affect both the formation of the BO and the projection of the $\mathrm{BN}$}

Mutations in six different genes cause aberrations in BO formation (Table 1; Fig. 4). In these mutants, the BO cells fail to form a tight cluster of 12 photoreceptor cells, but retain their photoreceptor identity as revealed by their expression of the photoreceptor-specific marker Chaoptin (Fig. 4A-D, H-L).

In embryos homozygous for any of these mutations, the BO cells are either only loosely associated or displaced along the BN pathway (Fig. 4A,H). Interestingly, all these mutations also show characteristic aberrations in the $\mathrm{BN}$ projection. In particular, they show defasciculation of the BN, which results in the formation of ectopically projecting nerve branches. In one mutant of this group, aloof (alf) axonal projections fail to project to P1. In all the other mutants of this group, defasciculation of the BN occurs after P1 has been reached; scattered $(s c d)$ is shown as an example.

\section{The scattered (scd) mutation disrupts cohesion of the $\mathrm{BO}$ and pathfinding of the BN}

The phenotype of $s c d$ is exemplary for the group of mutations

Fig. 7. $p k l$ causes sprouting and misprojections of the $\mathrm{BN}$ at $\mathrm{P} 2$. (A-E) $\mathrm{BN}$ projection in stage 16 embryos visualized by $\alpha-\mathrm{Bsh} / 22 \mathrm{C} 10$ double $(\mathrm{A}-\mathrm{C})$ and $22 \mathrm{C} 10$ single stainings (D-E). (F) $\alpha$ - $\beta$-galactosidase/22C10 double staining of a stage 16 embryo heterozygous for the $p k l$ enhancer trap insertion P3203. Shown are ventral $(\mathrm{A}-\mathrm{C}, \mathrm{F})$ and ventrolateral $(\mathrm{D}, \mathrm{E})$ views of the OLA area. (A) In a wild-type embryo, the BN projects as a single fasciculated nerve to the Bshexpressing cell at P2. Sometimes, individual axons can be found directly contacting the Bsh-expressing cell (arrowhead). (B,C) In $p k l$ mutant embryos, the $\mathrm{BN}$ grows beyond the Bsh-expressing cell. (B) The $\mathrm{BN}$ often splits (arrowheads) and the nerve branches or, as in $\mathrm{C}$, the entire nerve grow around and beyond the Bsh-expressing cell. (D,E) The sprouting of the $\mathrm{BN}$ results in various branching patterns, however, none of the branches grow into the central brain. Note that ingrowth into in the central brain should occur perpendicular to the optical plane shown here.
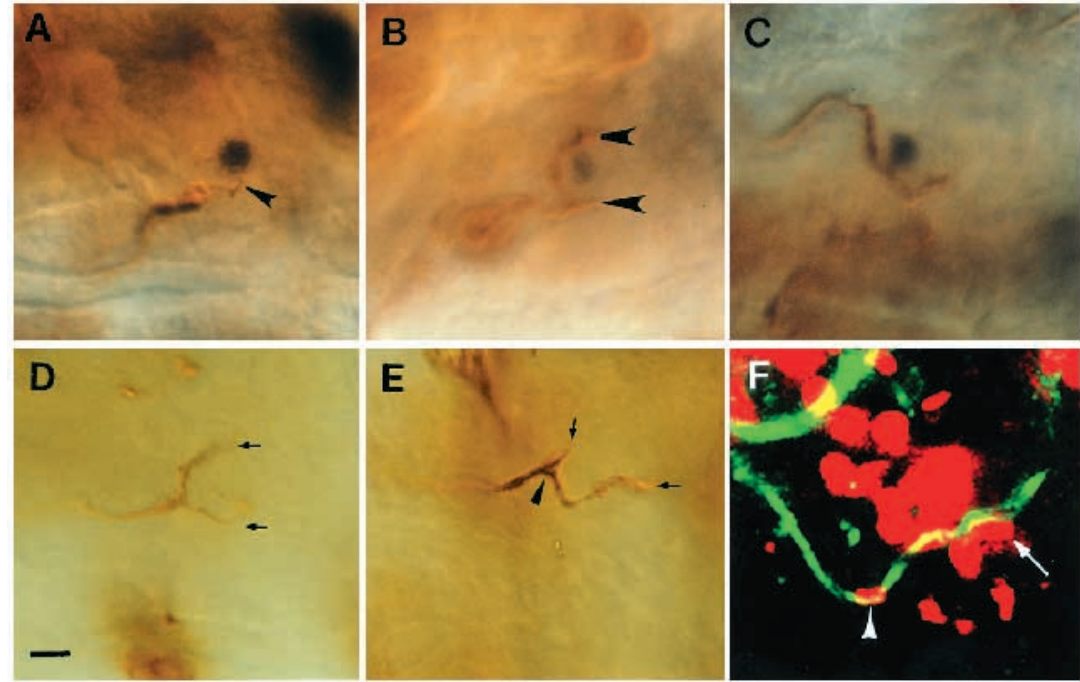

However, the aberrant BN branches, visible in B-E, extend parallel to the OLA/brain surface. (F) In embryos heterozygous for the $p k l$ enhancer trap insertion P3203, several $\beta$-galactosidase-expressing cells (arrow and arrowhead) are found in the OLA. The cells appear to be in direct contact with the BN. Scale bar, $10 \mu \mathrm{m}$ (A-C); $16 \mu \mathrm{m}$ (D-F). 
that affect both the formation of the $\mathrm{BO}$ and the projection of the BN (see Table 1). In scd mutant embryos a variable number of photoreceptors is displaced posteriorly along the path of the BN (Fig. 4A,B), and the normally tight fasciculation of $\mathrm{BN}$ axons is disrupted. The projection to P1 is still intact, but aberrant nerve branches are observed in the projection to P2 (Fig. 4C,D). In addition, we observe the formation of bifurcated nerve branches, which split and rejoin in the region of the OLA (Fig. 4C,D). Based on $\alpha$-FasII stainings, both the eOS and the OLA are morphologically normal in scd mutant embryos (not shown).

The scd mutation is a lethal $\mathrm{P}$ element insertion (l(3)3550) at chromosomal position 88E8-9 (BDGP; Hartl et al., 1994). The lethality of the mutation as well as the disruption of the $\mathrm{BN}$ can be reverted by $\mathrm{P}$ element excision, indicating that the mutation is caused by the $\mathrm{P}$ element insertion. As the genetic locus is not uncovered by an existing chromosomal deficency, we could not assess whether the mutation scd represents a complete loss-of-function allele for the locus. We generated four new X-ray alleles, which fail to complement the original scd mutation and are likely to represent small deficiencies including the scd locus (D. S. and U. G., unpublished data, Materials and Methods). In embryos that carry the scd mutation in trans over the X-ray alleles, the expressivity but not the severity of the BN phenotype is enhanced compared to the homozygotes. Thus, the scd mutation represents a strong hypomorphic rather than a complete loss-of-function allele of the locus.

The scd enhancer trap line $\mathrm{P} 3550$ shows $\beta$-galactosidase reporter gene expression during embryogenesis. During stages 15 and 16, expression is found in some cells of the eOS and OLA (Fig. 4E-G). These $\beta$-galactosidase-expressing cells are in direct contact with the $\mathrm{BN}$ along the major part of its pathway (Fig. 4G). Based on their co-expression of the gliaspecific marker, Repo, the P3550-positive cells in the eOS are glia cells (not shown), whereas the P3550-positive cells of the OLA, which are located at the base of the eOS are likely to represent neuronal cells as judged by their morphology. In addition, $\beta$-galactosidase expression is observed in cells of the developing nervous system and appears to be most prominent in glial cells associated with axonal projections, such as the exit glia and midline glia of the embryonic CNS (not shown). Barring the possibility that the $\mathrm{P} 3550$ enhancer trap is reporting the expression of a gene other than the one it disrupts ( $s c d$ ), this finding suggests that $s c d$ gene activity is in fact required in cells of the eOS rather than in the BO neurons themselves. Considering the $\mathrm{BO}$ and $\mathrm{BN}$ defects observed in the scd mutant, the finding suggests that cells of the eOS play a vital role in the formation of the $\mathrm{BO}$ and the pathfinding of the $\mathrm{BN}$.

\section{The aloof (alf) mutation affects cell clustering and leads to random projections of the $\mathrm{BN}$}

In alf mutant embryos the BO cell clustering is abnormal. However, the defects are different from those observed in the other mutants from this group (compare Fig. 4A and H,K). In most alf mutant embryos, we find two groups of cells, one of which represents a loose assembly of cells lying anteriorly or laterally to a relatively well organized cluster of BO cells (Fig. $4 \mathrm{H}, \mathrm{K})$. In addition, the $\mathrm{BN}$ projection is severely affected in alf mutant embryos. Only some of the photoreceptor axons fasciculate, project to P1 and grow toward P2, while a subset of
BO axons (2-4) show random projections (Fig. 4I,J). In 10\% of the mutant embryos, we observe photoreceptor axons that project anteriorly and explore areas far remote from the brain. Some of these axons develop enlarged axonal tips, most likely exaggerated growth cones (Fig. 4I). In some cases, it is clear that the randomly projecting axons originate from the abnormally oriented and slightly displaced cells, which are part of a mutant BO (Fig. 4J,K). It is important to note that these neurons have not lost their photoreceptor identity, as they still express Chaoptin (Fig. 4H-L). As observed with the scd mutant, the eOS and the OLA appear intact, consistent with the observation that in all alf mutant embryos some of the $\mathrm{BN}$ axons are still capable of projecting to P1 and toward P2. However, even these axons show defasciculation (Fig. 4L), while still in contact with the OLA. A detailed genetic analyis of this locus has not yet been undertaken.

\section{Mutations that affect only BN projection}

Mutations in seven complementation groups cause BN projection defects without affecting BO formation (Table 1; Figs 57). The mutants of this group all show defasciculation and aberrant projections of the BN. These mutants differ, however, with respect to the developmental time at which phenotypic aberrations are first observed and with respect to the position at which these defects occur along the path of the BN. The earliest defects can be detected in abstrakt (abs) mutants, which display abnormalities as soon as axonogenesis begins (Fig. 5). Mutations in two genes (including pnt) show defects later, when the $\mathrm{BN}$ is growing toward $\mathrm{P} 2$ (Table 1; Figs 6, 7). Mutations in pumuckel ( $p k l)$ and three other genes (Table 1) display defects still later, when the $\mathrm{BN}$ reaches $\mathrm{P} 2$.

\section{abs mutations affect early axonal growth and $\mathrm{BN}$ navigation}

abs mutant embryos form an intact BO (Fig. 5A,B). Defects in $\mathrm{BN}$ development become evident shortly after the onset of axonal outgrowth (Fig. 5C; compare with Fig. 3B,D). While in wild-type embryos the outgrowing $\mathrm{BN}$ axons rapidly fasciculate and project as a tightly fasciculated nerve straight to position P1, abs mutant embryos show 2-3 axon bundles. These aberrant bundles explore a much broader brain surface area (Fig. 5C-G). In more than $50 \%$ of mutant embryos, the nerve branches of mutant BNs deviate between $45^{\circ}$ and $60^{\circ}$ from their normal direction (Fig. 5D), resulting in severely branched nerves. While, in all mutant embryos, the nerve branches remain close to or in contact with the OLA, most nerve branches fail to reach position P2 (Fig. 5D). The few BN branches that eventually reach this position do not follow the normal path. Instead, they show abrupt directional changes along their projection (Fig. 5C,F). We often observe that the distal-most portion of the $\mathrm{BN}$ branches are significantly thicker than in wild type (Fig. 5C,F,G) and that they contain fine filopodia-like axonal extensions (Fig. 5F,G). These extensions cover an area of several cell diameters in the region of the OLA (Fig. 5G), suggesting that the BN axons of abs mutant embryos display an enhanced searching behavior as compared to wildtype BN axons. As judged by $\alpha$-FasII- and $\alpha$-Bsh-stainings, the eOS, the OLA and P2 are morphologically intact in $a b s$ mutant embryos.

The abs locus is represented by an EMS allele (IIFI) and a $\mathrm{P}$ allele (l(3)4505; BDGP; Hartl et al., 1994). The BN 
phenotype of the EMS allele $I I F-1$ is not enhanced in trans to a deficiency for the region (Materials and Methods), suggesting that $I I F-1$ represents a strongly hypomorphic if not complete loss-of-function allele of the abs locus. l(3)4505 contains a single lethal P enhancer trap insertion at chromosomal location 82A1 (BDGP, Hartl et al., 1994), which can be reverted to wild type by $\mathrm{P}$ element excision. Unfortunately no embryonic reporter gene expression pattern is seen in the l(3)4505 $\mathrm{P}$ enhancer trap line. Thus, we have no indication whether the $a b s$ gene activity is required in cells of the $\mathrm{BO}$ or in the surrounding cells, such as the eOS or the OLA. Nevertheless, our results demonstrate that $a b s$ is essential for the directed and fasciculated outgrowth of the BN early on, as well as its navigation at later stages.

\section{pnt causes defasciculation of the BN between P1 and P2}

In pnt mutant embryos, the $\mathrm{BN}$ initially fasciculates and projects normally. However, during its growth from P1 to P2, defasciculation of the $\mathrm{BN}$ and misrouting (Fig. 6A-C) of the two to three resulting nerve branches (Fig. 6C) are observed. The aberrant BN branches grow on the surface of the OLA and their endings reach various ectopic positions during mid-stage 16. Interestingly, we find that, in $80 \%$ of the examined mutant brain hemispheres, the Bsh-expressing cell, which is normally found at position $\mathrm{P} 2$, is either missing or mislocalized, while other Bsh-expressing cells appear in their normal positions (Fig. 6B,C). The aberrant BN branches never reach any of the other Bsh-expressing cells. As judged by $\alpha$-FasII stainings, the eOS and the OLA are present in pnt mutant embryos, although some OLA cells appear to express lower levels of FasII (not shown). In all our experiments, we have used the complete loss-of-function allele $p n t^{\Delta 88}$ (Klämbt, 1993).

The pnt gene encodes an ets-domain containing transcription factor. In the embryonic CNS, pnt is required in the glial cells that are involved in the formation of the anterior and posterior commissures (Klämbt, 1993). We examined pnt expression by monitoring $\beta$-galactosidase expression in the $p n t$ $\mathrm{P}$ enhancer trap lines $l(3) 7825$ and $\mathrm{rM} 254$, which represent insertions in the two different promoters of the pnt gene (O’Neill et al., 1994; Klaes et al., 1994). During stages 14-16, a few $\beta$-galactosidase-positive cells are found along the entire path of the BN (Fig. 6D). In addition, a few $\beta$-galactosidasepositive cells are found close to $\mathrm{P} 2$ (Fig. 6E). Interestingly, one of these cells near P2 is contacted by the tip of the nerve at stage 16 (Fig. 6E). Based on their morphology, some of the pnt-expressing cells are likely to represent glial cells. We cannot exclude the possibility that pnt is expressed in additional cells in the environment of the $\mathrm{BN}$, since the two $\mathrm{P}$ enhancer trap lines together do not report the entire pattern of pnt gene expression (C. Klämbt, personal commmunication). These results suggest that pnt gene function is required in cells along the path of the $\mathrm{BN}$, as well as in the $\mathrm{P} 2$ region for the proper pathfinding of the nerve.

\section{$p k l$ affects the projection of the $\mathrm{BN}$ at $\mathrm{P} 2$}

In embryos mutant for the $p k l$ mutation, as well as three other mutations (see Table 1), the BN is properly fasciculated and follows its normal path until it approaches position P2. However, instead of taking its normal turn into the central brain, the $\mathrm{BN}$ undergoes terminal sprouting in the $\mathrm{P} 2$ area. This leads to the formation of several independent nerve branches (Fig. 7A-E), which remain on the brain surface (Fig. 7B-E). In about $20 \%$ of the mutant embryos defasciculation of the $\mathrm{BN}$ is visible prior to reaching P2. Based on $\alpha$-FasII stainings, we do not find any morphologically visible abnormalities in the tissues associated with the $\mathrm{BN}$, such as the eOS or the OLA (not shown), and the Bsh-expressing cell is present in its normal position as revealed by $\alpha$-Bsh/22C10 double stainings. Considering that the wild-type $\mathrm{BN}$ displays searching behavior in the P2 area, these findings suggest that an essential spatial cue is missing at $\mathrm{P} 2$ or that the $\mathrm{BN}$ has lost its ability to recognize this cue.

$p k l$ is a single semilethal $\mathrm{P}$ element insertion at chromosomal position 85D1-2 (l(3)3203; BDGP; Hartl et al., 1994), which likely represents a strong hypomorphic if not complete loss-of-function allele of the $p k l$ locus (Materials and Methods).

The $p k l$ enhancertrap line P3203 shows weak expression in the posterior head of stage 11 embryos (not shown), covering the region that will give rise to OLA and BO precursor cells during stages 12 and 13. During stages 14-16, the $\beta$-galactosidase reporter gene is also strongly expressed in cells that are associated with the BN close to position P2 (Fig. 7F). Based on their morphology, these P3203-positive cells are likely to represent glial cells. $\alpha$ - $\beta$-galactosidase $/ \alpha$-Bsh double stainings confirm that none of the P3203-positive cells are identical with the Bsh-positive cell at P2 (not shown). However, we have not been able to determine whether any are identical with the pntpositive cells close to position $\mathrm{P} 2$. In any case, the expression of the pkl enhancer trap line P3203 in cells located in the P2 area correlates well with the appearance of phenotypic defects at P2 in the homozygous mutant embryos, suggesting a role for $p k l$ in providing a permissive substratum or a directional cue for axonal growth at position P2.

\section{DISCUSSION}

The developmental and genetic analysis of the $\mathrm{BO} / \mathrm{BN}$ system has led to the identification of several cellular components that are part of the BN pathway and revealed developmental strategies employed in the establishment of the $\mathrm{BN}$ projection.

\section{Development of the BO and the eOS}

Several lines of evidence suggest that the cells of the BO and the OLA are derived from a common pool of precursor cells. At embryonic stage 12 , the $K r$-positive BO precursors are found immediately adjacent to disco-positive OLA precursor cells in the posterior head. However, the two cell populations co-express both the sine oculis (so) gene (Cheyette et al., 1994; Serikaku and O'Tousa, 1994) and the cell surface marker FasII (Grenningloh et al., 1991). Furthermore, the fate of OLA precursors is readily switched to that of BO cells as is observed in patched (ptc) mutant embryos (Schmucker et al., 1994), suggesting the existence of a common origin for the two cell types.

During the morphogenetic separation of BO and OLA first by optic lobe invagination and later by head involution, the two structures remain in contact through a cellular bridge, which we term the embryonic optic stalk (eOS). Some of the eOS cells may later differentiate into glial cells, because a string of Repo-positive glia is found lining the path of the BN along the 


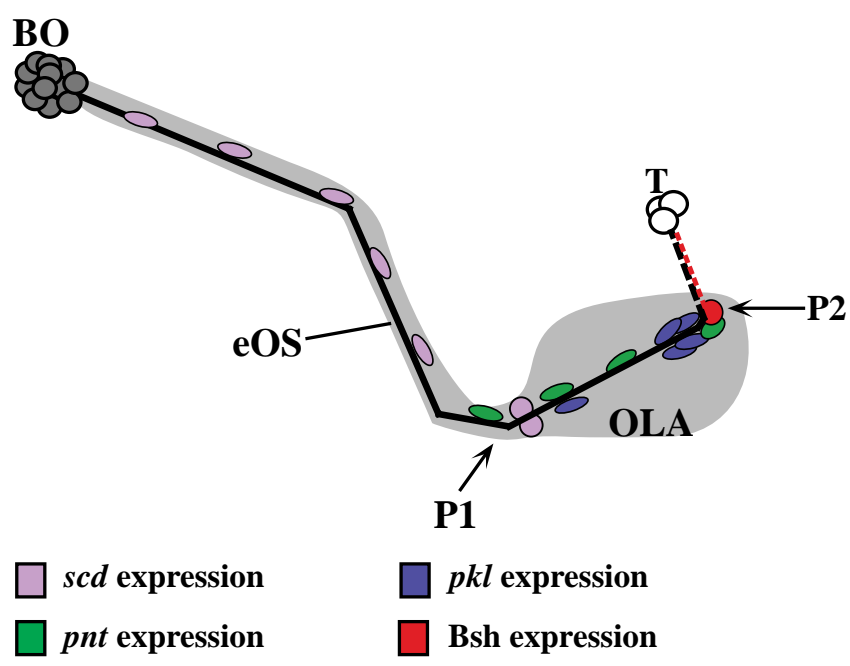

Fig. 8. Schematic representation of the stage $16 \mathrm{BN}$ projection. Cellular components in contact with the nerve include glial (oval) and neuronal (circle) cells. In the case of $s c d$, pnt and $p k l$, the expression data are based on reporter gene expression of $\mathrm{P}$ enhancer trap insertions. For further description see text.

eOS at stages 16 and 17 (see Fig. 8 and Campos et al., 1995). Alternatively, the precursors of these glia may migrate to the eOS from elsewhere. However, since the lineage of the glia in the embryonic head has not been traced, we cannot discriminate between these two possibilities. Furthermore, we have not followed the fate of the eOS through postembryonic stages of development. It will be very interesting, however, to examine whether the cells of the eOS persist into larval stages and how they relate to the larval optic stalk (Meinertzhagen and Hanson, 1993), whose function it is to funnel the developing adult photoreceptor axons into the optic lobe.

\section{Development of the BN projection}

The establishment of the BN projection occurs in three distinct steps and involves at least two different modes of axonal growth. BN axons first project toward the intermediate target P1 by directed growth at their tip. Once the distal tip of the BN has reached P1, a substantial elongation of the nerve occurs, which likely is brought about by intercalary growth. Concomitant with the elongation of the nerve, the $\mathrm{BN}$ resumes its directed growth at the tip and projects first to P2 and then into the central brain. During this second phase of directed growth, the BN takes two sharp turns, the first at P1 and the second at $\mathrm{P} 2$.

The fidelity of the first step, the projection of the BN to P1, is ensured by the formation of the eOS, which serves as a cellular substratum for the growth of the BN. The formation of a cellular bridge provides an effective developmental strategy to facilitate axonal pathfinding which has not been described for any other nerve pathway in the Drosophila embryonic PNS or CNS. Later on, the cells of the eOS may be important for stabilizing the axon bundle or for anchoring the axons to the OLA during the subsequent massive elongation of the BN.

During the second phase of directed growth, the OLA provides the cellular substratum for growth. However, the analysis of the wild type did not provide any specific insights as to which cues are responsible for reorienting the growth of the $\mathrm{BN}$ at $\mathrm{P} 1$. In contrast, $\mathrm{P} 2$ likely serves a function as a guidepost directing fibers into the central brain, since nerve growth stalls at $\mathrm{P} 2$ and individual processes are found exploring the area.

The oriented growth of the $\mathrm{BN}$ to $\mathrm{P} 1$ and then to $\mathrm{P} 2$ occurs in a sequential fashion, that is, one or very few axons grow first, while others follow. In a number of systems, leading fibers have been reported to serve as pioneers for the pathfinding of the follower axons (Goodman and Shatz, 1993; Bentley and Keshishian, 1982). However, in the case of the BN, we have not been able to determine whether the leading fibers are invariably generated by (a) specific neuron(s) of the BO, since subset-specific fiber markers have not been identified for the BN. Thus, we cannot exclude the possibility that the axons simply grow at different rates, and perhaps lead alternately. Interestingly, all axons stall for some time upon reaching $\mathrm{P} 2$, suggesting that $\mathrm{P} 2$ not only serves to guide the axons into the central brain, but also to synchronize their growth.

\section{Mutations affecting both the formation of the $\mathrm{BO}$ and the projection of the BN}

The mutations that we isolated in our screen fall into two broad phenotypic groups. In the first group of mutants, both the BO and the projection of the $\mathrm{BN}$ are affected, while in the second group only the BN projection is abnormal.

The fact that we find an entire group of mutations (Table 1) that affect both the formation of the $\mathrm{BO}$ and the pathfinding of the $\mathrm{BN}$ emphasizes the close link between the two processes. Based on the observation that phenotypic defects in the BO only become visible while the massive elongation of the $\mathrm{BN}$ is taking place during stages 14 to 16 , we favor the following interpretation. The disruption of the $\mathrm{BO}$ may largely be a consequence of the mechanical stress applied to both the $\mathrm{BN}$ and the BO during their morphogenetic separation in head involution. It is possible that this mechanical stress exacerbates developmental defects that would otherwise be less apparent such as reduced cohesion within the $\mathrm{BN}$ bundle or reduced adhesion to P1. The expression of scd enhancer trap line P3550 in glial cells of the eOS and in cells of the OLA at the base of the eOS is consistent with this interpretation. The glia surrounding the $\mathrm{BN}$ along the eOS may play a crucial role in establishing or maintaining proper cohesion of the nerve, while the cells at the base of the eOS are required for its adhesion to P1. Whether the projection defects of the BN on the OLA surface observed in the $s c d$ mutant could also be attributed to defects in the eOS glia or the cells at the base of the eOS is less obvious. However, it is interesting to note that some of the phenotypic defects observed in disco mutant embryos are strikingly similar (Steller et al., 1987) to those found in scd. disco is also expressed in the eOS and required there for the proper differentiation of glial cells (Campos et al., 1995).

In a different example of this group of mutants, alf, a subset of BO cells is not properly integrated into the main cluster and projects randomly, while the major part of the $\mathrm{BO}$ projects toward P1 and P2. It is quite likely that some of the BO cells fail to obtain their proper orientation in the cluster and therefore fail to project along the eOS. However, the cause of the projection defects observed in the portion of the $\mathrm{BN}$ that succeeds in projecting to the OLA is presently unclear. Remarkably, this is the only mutation from our screen that 
shows random projections. In all other cases, abnormal projections retain contact either with the OLA or the brain surface.

\section{Mutations affecting only the BN projection}

The phenotypic defects of the mutants that affect only the BN projection share similarities, in that they all show defasciculation of the $\mathrm{BN}$ and aberrant projections of the resulting nerve branches. However, in the different mutants, phenotypic defects occur at different stages of the BN projection, suggesting that distinct cellular and molecular mechanisms are involved in each of the three steps of BN development.

In $a b s$ mutants, defasciculation of the BN occurs with the onset of axonogenesis, when independent nerve branches are established. However, since at later stages one may find a single nerve bundle, branches may either be retracted or refasciculate. The latter possibility would suggest that the system is capable of compensating for mistakes. In addition, the morphology of the nerve tip is highly abnormal in $a b s$ mutants and shows enormous growth-cone-like structures and filopodial extensions, which we have never observed in either wild-type or other mutant backgrounds. These abnormally large extensions may reflect defects in the capacity to withdraw extensions or may reflect an exaggerated search behavior. As we have not gained any insights into the expression pattern of $a b s$, we cannot assess whether the gene is required in the cells of the $\mathrm{BO}$ or in the cells of the OLA.

In the majority of the mutants in this group, phenotypic defects are found later, either on the way between P1 and P2 $(p n t)$, or at $\mathrm{P} 2(p k l)$. The phenotypic defects observed in $p n t$ mutants correlate with the location of pnt-positive cells. In the wild type, pnt is expressed in presumed glia along the path of the BN, mostly between P1 and P2, which is where the BN axons defasciculate in the homozygous mutant. pnt is also expressed in presumed glia in the $\mathrm{P} 2$ region. In the homozygous mutant, there is often no Bsh-expressing cell at P2, suggesting that pnt function is required in the neighboring cells for induction of Bsh-expression in the cell at P2. Similarly, pnt has been reported to be required in glial cells of the embryonic CNS for the induction of the neuronal marker $22 \mathrm{C} 10$ in the MP2 cells (Klaes et al., 1994).

In $p k l$ embryos, both the Bsh-positive cell and the putative $p k l$-positive cells, which likely represent glial cells, are still present at their normal position. However, the axons of the BN do not seem to recognize P2. Instead of growing straight toward the Bsh-positive cell and stopping there, the BN axons grow beyond the Bsh-cell and begin with an abnormal search behavior in the $p k l$ mutant. These phenotypic defects corroborate the notion that $\mathrm{P} 2$ plays a dual role of growth inhibitor and guidepost. The putative expression pattern of $p k l$ furthermore suggests that the $\mathrm{P} 2$ position consists of several cellular components, including the Bsh- and the putative $p k l$-positive cells. It is possible that these components are required individually for proper pathfinding of the nerve. Alternatively, the putative $p k l$-positive glial cells may be required for proper development or differentiation of the Bsh cell as guidepost.

\section{Concluding remarks}

An interesting result from our mutant analysis is that all the mutants that we found show defasciculation of the nerve in conjunction with misprojection of the nerve's branches. We believe that the defasciculation of the nerve observed in our mutants is mainly a consequence of impaired pathfinding. As a consequence of missing cues or an impaired capacity to sense cues, individual fibers or groups of fibers undertake an independent exploration of the environment, thereby foregoing fasciculation with the bundle. It is quite possible that the fibers of the nerve bundle communicate to ensure concerted growth. Leading axons would signal to following axons that their pathfinding is successful, thereby reinforcing the fasciculated growth of the followers. Such positive feedback would not occur if the leading fibers fail to receive the proper cues.

The fact that in each subgroup of mutants projection defects are observed at different stages of $\mathrm{BN}$ development strongly suggests that distinct mechanisms are involved in the different steps of BN pathfinding. This interpretation is further corroborated by our finding that the genes disrupted by these mutations are likely to be expressed in different cellular components along the path of the $\mathrm{BN}$. These cellular components include glial cells in the eOS, a few, presumably, neuronal cells at the base of the eOS, presumptive glia on the OLA and, finally, a complex of neuronal and glial cells at the nerve's entry point into the brain. The presumptive glia on the OLA and the complex of cells at P2 may be required for proper pathfinding of the BN on the OLA surface and for its entry into the brain. The molecular characterization of the mutants promises to provide important insights into the mechanisms of BN pathfinding and nervous system development.

We are very grateful to Corey Goodman, Michael Hoch, Christian Klämbt and Elisabeth Knust for providing various antibodies. We would also like to thank Chris Doe, Fernando Jimenez, Christian Klämbt and the Bloomington and Tübingen Stock Centers for fly strains. In addition, we would like to thank Hermann Steller and Mary Beth Hatten for generously providing access to their confocal microscopy facilities. This project was supported by the Max-PlanckSociety (H. J.), a Karl-von-Frisch Award from the German Zoology Society (H. J. and D. S.), a National Eye Institute James A. Shannon Director's Award (1R55EY/OD11560-01; U. G.), and fellowships from the German National Science Foundation and the European Molecular Biology Organization (D. S.)

\section{REFERENCES}

Bate, M. and Broadie, K. (1995). Wiring by fly: the neuromuscular system of the Drosophila embryo. Neuron 15, 513-525.

Bentley, D. and Keshishian, H. (1982). Pathfinding by peripheral pioneer neurons in grasshoppers. Science 218, 1082-88.

Bolwig, N. (1946). Senses and sense organs of the anterior end of the house fly larva. Vidensk. Medd. fra. Dansk. Naturh. Foren. 109, 80-212.

Campbell, G., Goring, H., Lina, T., Spana, E., Anderson, S., Doe, C. Q. and Tomlinson, A. (1994). RK2, a glial-specific homeodomain protein required for embryonic nerve cord condensation and viability in Drosophila. Development 120, 2957-2966.

Campos, A. R., Lee, K. J. and Steller, H. (1995). Establishment of neuronal connectivity during development of the Drosophila larval visual system. $J$. Neurobiology 28, 313-329.

Campos-Ortega, J. A. and Hartenstein, V. (1985). The Embryonic Development of Drosophila melanogaster. Berlin: Springer-Verlag.

Cheng, H.-J., Nakamoto, M., Bergemann, A. D. and Flanagan, J. C. (1995). Complementary gradients in expression and binding of ELF-1 and Mek4 in development of the topographic retinotectal map. Cell 82, 371-81.

Cheyette, B. N. R., Green, P. J., Martin, K., Garren, H., Hartenstein, V. and Zipursky, S. L. (1994). The Drosophila sine oculis locus encodes a homeodomain-containing protein required for the development of the entire visual system. Neuron 12, 977-996. 
Dodd, J. and Jessell, T. M. (1988). Axon guidance and the patterning of neuronal projections in vertebrates. Science 242, 692-699.

Doe, C. Q., Chu-LaGraff, Q., Wright, D. M. and Scott, M. P. (1991). The prospero gene specifies cell fates in the Drosophila central nervous system. Cell 65, 451-464.

Drescher, U., Kremoser, C., Handwerker, C., Loeschinger, J., Noda, M. and Bonhoeffer, F. (1995). In vitro guidance of retinal ganglion cell axons by RAGS, a $25 \mathrm{kDa}$ tectal protein related to ligands for Eph receptor tyrosine kinases. Cell 82, 359-70.

Freeman, M., Klämbt, C., Goodman, C. S. and Rubin, G. M. (1992). The argos gene encodes a diffusible factor that regulates cell fate decisions in the Drosophila eye. Cell 69, 963-975.

Fujita, S. C., Zipursky, S. L., Benzer, S., Ferrus, A. and Shotwell, S. L. (1982). Monoclonal antibodies against Drosophila nervous system. Proc. Nat. Acad. Sci. USA 79, 7929-7933.

Goodman, C. S. (1996). Mechanisms and molecules that control growth cone guidance. Annu. Rev. Neurosci. 19, 341-77.

Goodman, C. S. and Shatz, C. J. (1993). Developmental mechanisms that generate precise patterns of neuronal connectivity. Cell 10, 77-98.

Green, P., Yanoussi-Hartenstein, A. and Hartenstein, V. (1993). The embryonic development of the Drosophila visual system. Cell Tissue Res. 273, 583-598.

Grenningloh, G., Bieber, A., Rehm, J., Snow, P., Traquina, Z., Hortsch, M., Patel, N. and Goodman, C. S. (1990). Molecular genetics of neuronal recognition in Drosophila: Evolution and function of immunoglobulin superfamily cell adhesion molecules. Cold Spring Harbor Symp. Quant. Biol. 55, 327-340.

Grenningloh, G., Rehm, E. J. and Goodman, C. S. (1991). Genetic analysis of growth cone guidance in Drosophila: fasciclin II functions as a neuronal recognition molecule. Cell 67, 45-57.

Grumet, M. (1991). Cell adhesion molecules and their subgroups in the nervous system. Curr. Opin. Neurobiol. 1, 370-76.

Hartl, D. L., Nurminsky, D. I., Jones, R. W. and Lozovskaya, E. R. (1994). Genome structure and evolution in Drosophila: Applications of the framework P1 map. Proc. Nat. Acad. Sci. USA 91, 6824-29.

Heilig, J., Freeman, M., Lee, K. and Steller, H. (1991). Isolation and cloning of the disconnected gene of Drosophila. EMBO J. 10, 809-815.

Hoch, M., Broadie, K., Jäckle, H. and Skaer, H. (1994). Sequential fates in a single cell are established by the neurogenic cascade in the Malpighian tubules of Drosophila. Development 120, 3439-3450.

Hoch, M., Seiffert, E., Jäckle, H. (1990). Cis-acting control elements for Krüppel gene expression in the Drosophila embryo. EMBO J. 9, 2587-2595.

Jones, B. and McGinnis, W. (1993). A new Drosophila homeobox gene, bsh, is expressed in a subset of brain cells during embyogenesis. Development 117, 793-806.

Kennedy, T. E., Serafini, T., de la Torre, J. R. and Tessier-Lavigne, M. (1994). Netrins are diffusable chemotropic factors for commissural axons in the embryonic spinal cord. Cell 78, 425-436.

Klaes, A., Menne, T., Stollewerk, A., Scholz, H. and Klämbt, C. (1994). The ets transcription factors encoded by the Drosophila gene pointed direct glial cell differentiation in the embryonic CNS. Cell 78, 149-160.

Klämbt, C. (1993). The Drosophila gene pointed encodes two ets like proteins, which are involved in the development of the midline glial cells. Development 117, 163-176.

Klämbt, C., Jacobs, R. J. and Goodman, C. S. (1991). The midline of the Drosophila CNS: model and genetic analysis of cell lineage, cell migration, and development of commissural axon pathways. Cell 64, 801-815.

Kolodkin, A. L., Matthes, D. J. and Goodman, C. S. (1993). The semaphorin genes encode a family of transmembrane and secreted growth cone guidance molecules. Cell 75, 1389-99.

Kolodziej, P., Jan, L. Y. and Jan, Y. N. (1995). Mutations that affect the length, fasciculation, or ventral orientation of specific sensory axons in the Drosophila embryo. Neuron 15, 273-86.

Kretzschmar, D., Brunner, A., Wiersdorff, V., Pflugfelder, G. O., Heisenberg, M. and Schneuwly, S. (1992). giant lens, a gene involved in cell determination and axon guidance in the visual system of Drosophila melanogaster. EMBO J. 11, 2531-9.
Lee, K. J., Freeman, M. and Steller, H. (1991). Expression of the disconnected gene during development of Drosophila melanogaster. EMBO J. 10, 817-26.

Lindsley, D. L. and Zimm, G. G. (1992). The Genome of Drosophila melanogaster. San Diego: Academic Press.

Lou, Y., Raible, D. and Raper, J. A. (1993). Collapsin: A protein in brain that induces the collapse and paralysis of neuronal growth cones. Cell 75, $217-$ 227.

Meinertzhagen, I. A. and Hanson, T. E. (1993). The development of the optic lobe. In The Development of Drosophila melanogaster (ed. M. Bate and A. Martinez-Arias), pp. 1363-1491. Cold Spring Harbor, New York: Cold Spring Harbor Laboratory Press.

Moses, K., Ellis, M. C. and Rubin, G. M. (1989). The glass gene encodes a zink-finger protein required by Drosophila photoreceptor cells. Nature 340, 531-536.

O'Neill, E. M., Rebay, I., Tjian, R. and Rubin, G. M. (1994). The activities of two ets-related transcription factors required for Drosophila eye development are modulated by the Ras/MAPK pathway. Cell 78, 137-147.

Roberts, D. B. (1986). Drosophila: A Practical Approach. Oxford: IRL Press.

Robertson, H. M., Preston, C. R., Phillis, R. W., Johnson, S. D., Benz, W. K. and Engels, W. R. (1988). A stable genomic source of P element transposase in Drosophila melanogaster. Genetics 118, 461-470.

Salzberg, A., D’Evelyn, D., Schulze, K. L., Lee, J.-K., Strumpf, D., Tsai, L. and Bellen, H. (1994). Mutations affecting the pattern of the PNS in Drosophila reveal novel aspects of neuronal development. Neuron 13, 269287.

Schmidt-Ott, U. and Technau, G. M. (1992). Expression of $e n$ and $w g$ in the embryonic head and brain of Drosophila indicates a refolded band of seven segment remnants. Development 116, 111-125.

Schmucker, D., Su, A. L., Beermann, A., Jäckle, H. and Jay, D. G. (1994). Chromophore-assisted laser inactivation of patched protein switches cell fate in the larval visual system of Drosophila. Proc. Nat. Acad. Sci. USA 91, 26642668 .

Schmucker, D., Taubert, H. and Jäckle, H. (1992). Formation of the Drosophila larval photoreceptor organ and its neuronal differentiation require continuous Krüppel gene activity. Neuron 9, 1025-1039.

Seeger, M. A. (1994). Genetic and molecular dissection of axon pathfinding in the Drosophila nervous system. Current Opinion in Neurobiology 4, 56-62.

Serafini, T., Kennedy, T. E., Galko, M. J., Mirzayan, C., Jessel, T. M. and Tessier-Lavigne, M. (1994). The netrins define a Family of axon outgrowthpromoting proteins homologousto C. elegans UNC-6. Cell 78, 409-424.

Serikaku, M. A. and O'Tousa, J. E. (1994). sine oculis is a homeobox gene required for Drosophila visual system development. Genetics 138, 1137-1150.

Simon, H. and Lumsden, A. (1993). Rhombomere-specific origin of the contralateral vestibulo-acoustic efferent neurons and their migration across the embryonic midline. Neuron 11, 209-220.

Steller, H., Fischbach, K. F., and Rubin G. M. (1987). disconnected: A locus required for neuronal pathway formation in the visual system of Drosophila. Cell 50, 1139-1153.

Tix, S., Minden, J. S. and Technau, G. M. (1989). Preexisting neuronal pathways in the developing optic lobes of Drosophila. Development 105, 739-746.

Vaessin, H., Grell, E., Wolff, E., Bier, E., Jan, L. Y. and Jan, Y. N. (1991). prospero is expressed in neuronal precursors and encodes a nuclear protein that is involved in the control of axonal outgrowth in Drosophila. Cell 67, 941-953.

VanVactor, D., Krantz, D. E., Reinke, R. and Zipursky, S. L. (1988). Analysis of mutants in chaoptin, a photoreceptor cell-specific glycoprotein in Drosophila, reveals its role in cellular morphogenesis. Cell 52, 281-290.

VanVactor, D., Sink, H., Fambrough, D., Tsoo, R. and Goodman, C. S. (1993). Genes that control neuromuscular specificity in Drosophila. Cell 73, 1137-1153.

Yanoussi-Hartenstein, A., Tepass, U. and Hartenstein, V. (1993). Embryonic origin of the imaginal discs of the head of Drosophila melanogaster. Roux's Arch. Dev. Biol. 203, 60-73.

(Accepted 9 December 1996) 